\title{
Chronic Intestinal Dysmotility (CID) Secondary to Consumption of Sushi: A Case Series and Literature Review
}

\author{
Vijaypal Arya $^{\mathrm{a}, \mathrm{b}, \mathrm{c}}$, Ashok Valluri ${ }^{\mathrm{b}}$, Priya Mahajan ${ }^{\mathrm{a}}$, Sateesh Kotturia ${ }^{\mathrm{a}}$, Shashideep Singhal ${ }^{\mathrm{b}}$
}

\begin{abstract}
Chronic intestinal dysmotility (CID) applies to abnormal contractions caused by uncoordinated muscular activity in the intestines. Various associations and hypotheses have been postulated, but the etiology of CID is not clear. We present a case series of four young patients aged 16 - 30 years who presented with non specific gastrointestinal symptoms of abdominal pains, nausea, vomiting and constipation. There was no radiological evidence of intestinal dilatation. Laboratory and endoscopic evaluation failed to reveal any clear etiology. Dietary history revealed frequent consumption of sushi by all four patients. Chronic mercury toxicity via frequent sushi consumption was postulated to be the possible etiology of CID in these patients. Patients were advised to stop further sushi consumption. They were treated symptomatically with acid suppressing medications, anti-emetics, analgesics, antispasmodics and laxatives as needed. A remarkable improvement in symptoms was seen within 2 - 3 months. The present article systematically reviews the underlying etiology and presentation of CID secondary to sushi consumption with a focus on its public health importance.
\end{abstract}

Keywords: Mercury; Sushi; Dysmotility

\section{Introduction}

An estimated 30 million people suffer from intestinal motility disorder in the United States. Worldwide, this condition constitutes up to $30-45 \%$ of all gastrointestinal (GI) conditions

\footnotetext{
Manuscript accepted for publication January 6, 2014

${ }^{\text {a}}$ Vijaypal Arya Gastroenterology PC, 75-54 Metropolitan Avenue, Middle Village, NY 11379, USA

bWyckoff Heights Medical Center, 374 Stockholm Street, Brooklyn, NY 11237, USA

${ }^{\mathrm{c} C o r r e s p o n d i n g ~ a u t h o r: ~ V i j a y p a l ~ A r y a, ~ C l i n i c a l ~ A s s i s t a n t ~ P r o f e s s o r ~ o f ~}$ Medicine, Cornell university, Endoscopy Unit, Wyckoff Heights Medical Center, Vijaypal Arya Gastroenterology PC, 75-54 Metropolitan Avenue, Middle Village, NY 11379, USA.

Email: varyamd@yahoo.com
}

doi: http://dx.doi.org/10.14740/jmc1688e
[1]. The disease spectrum may vary from the most common gastro-paresis and constipation, to a rare entity such as intestinal pseudo-obstruction. Constipation and related symptoms of bloating and abdominal discomfort are more common in females with a female to male ratio of 2.2:1 [2].The etiology which alters the neuronal and hormonal integrity of the GI tract is not clear.

Among the gastrointestinal dysmotilities, chronic intestinal pseudo-obstruction (CIPO) and chronic intestinal dysmotility (CID) constitute heterogeneous clinical syndromes with relapsing and remitting course. The clinical picture includes nausea, vomiting, abdominal pain, weight loss, constipation and changes in appetite. Literature search provided no information to differentiate these conditions based on duration or severity of clinical presentation. The key differentiating feature may be the intestinal dilatation on radiology - present in CIPO and absent in CID. Patients with CIPO generally experience obstructive symptoms mimicking mechanical obstruction without any mechanical cause or anatomic obstruction [3-5]. The duration of symptoms lasts for several days to months. Due to the non specific nature of presentation, a delay in diagnosis is not uncommon and sometimes necessitates frequent surgical interventions. Two specific patterns have been identified - neuropathic and myopathic (Table 1). Based on the underlying cause the neuropathic form may be idiopathic and acquired. The myopathic form may show a familial pattern. Recent literature associated CIPO with intake of or exposure to heavy metals, certain drugs and insecticides [6].

Methyl mercury (MeHg), a form of organic mercury $(\mathrm{Hg})$, with consumption of fish, is avidly absorbed from the GI tract. It crosses the blood brain barrier and interferes with central nervous system (CNS) function, causing psychological and neurological disturbances [7, 8]. Its central and peripherally mediated effects on the GI tract and its motility are not clearly understood. Lowenstein et al [9] confirmed an increase in public consumption of $\mathrm{Hg}$ due to high levels of the metal present in raw tuna fish used for sushi. Due to its neurotoxic nature, $\mathrm{Hg}$ in tuna sushi may have the potential to cause CID. The present case reports highlight the role of increased $\mathrm{Hg}$ intake in the form of sushi consumption as a possible causative factor for intestinal dysmotility. 


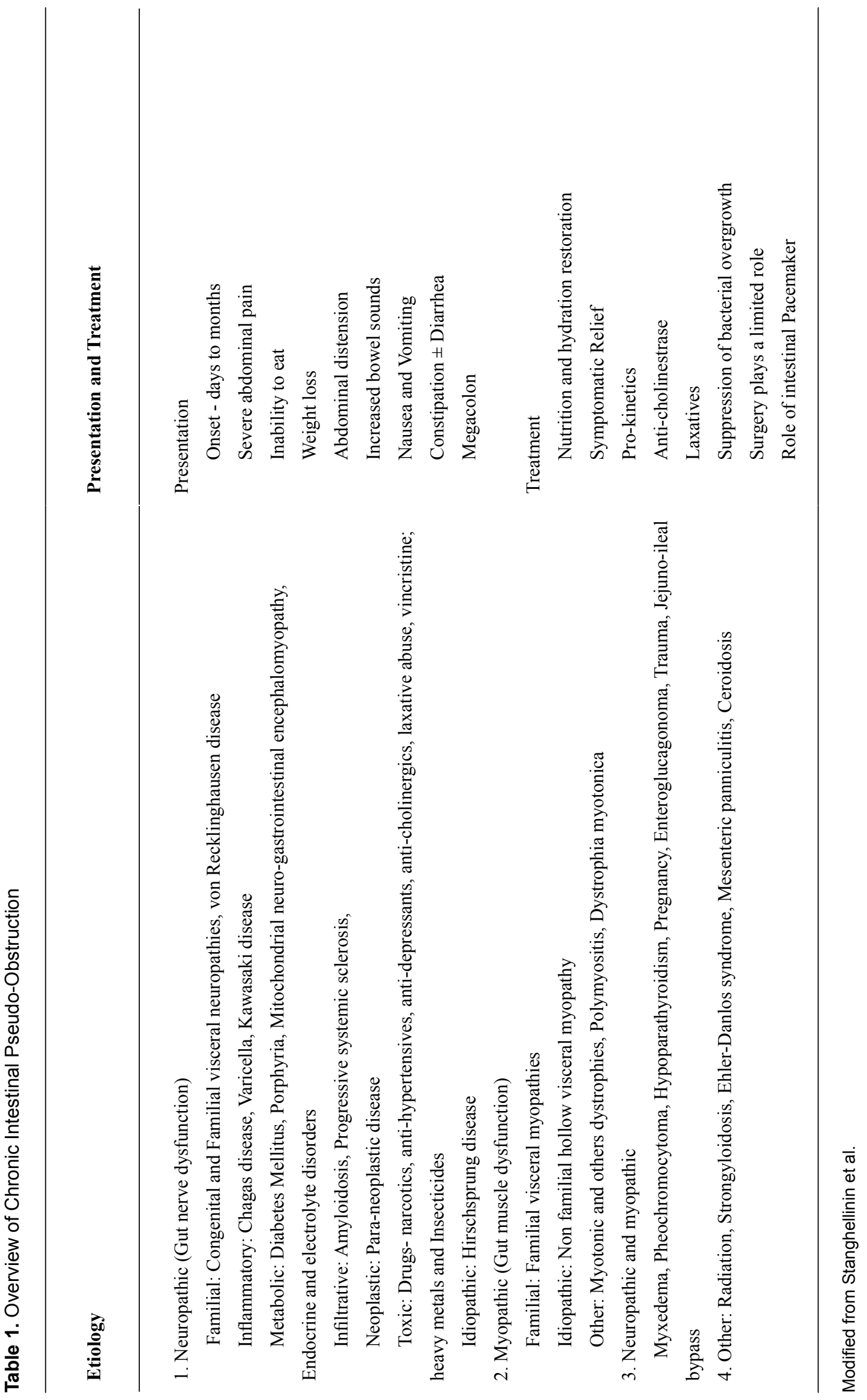




\section{Case Report}

\section{Case 1}

A 20-year-old female with past medical history (PMH) of asthma presented with severe constipation, abdominal pain, bloating, nausea, vomiting and headaches for two months. Her complaints started after a vacation during which she ate sushi every day for a period of $6-8$ weeks. On physical examination she appeared apprehensive with mild tenderness in the lower abdomen and decreased bowel sounds. She had frequently visited the emergency room due to the above complaints. Routine laboratory work up (complete blood counts (CBC), complete metabolic panel (CMP), amylase, lipase, coagulation profile, erythrocyte sedimentation rate (ESR), C-reactive protein (CRP), fecal occult blood test (FOBT) and stool tests - culture for ova, parasites and giardia antigen were negative. Special laboratory work up (anti-nuclear antibody, anti-neutrophil cytoplasmic antibody, anti-Hu antibody screening, Trypanosoma antibody assay and Saccharomyces cerevisiae antibody assay) was negative. CT abdomen and pelvis with and without contrast was unremarkable. Neurological examination, CT and MRI of the head were also normal. Her colonoscopy showed diffusely dilated colon with normal mucosa. The histopathology from multiple biopsies from terminal ileum and colon was normal. Esophago-gastro-duodenoscopy (EGD) revealed mild gastritis and gastro-esophageal reflux disease (GERD). She was treated symptomatically with low fiber diet, pro-kinetics, proton pump inhibitors, and tegaserod maleate, and she was advised to stop eating sushi. She was referred to a tertiary care center for further evaluation where gastric emptying study was performed and was normal. Over the next 6 - 8 weeks, patient's symptoms slowly subsided.

\section{Case 2}

A 16-year-old male with PMH of asthma presented with abdominal discomfort, pain in the epigastric region, constipation, 9-lb weight loss, post-prandial nausea and vomiting for 4 - 6 weeks. The patient's diet was significant for eating raw fish (sushi) over a period of 2 months before these complaints started. His physical examination was normal. His laboratory (CBC, CMP and ESR) and radiological work up was negative. EGD showed mild erythema, gastritis and GERD. Antral biopsy revealed mild chronic inflammation. Gastro-paresis was ruled out by solid phase gastric emptying study. He was started on liquid diet, pro-kinetic and proton pump inhibitor and advised to stop eating sushi. His symptoms improved in 2 months.

\section{Case 3}

A 26-year-old female presented with severe constipation for

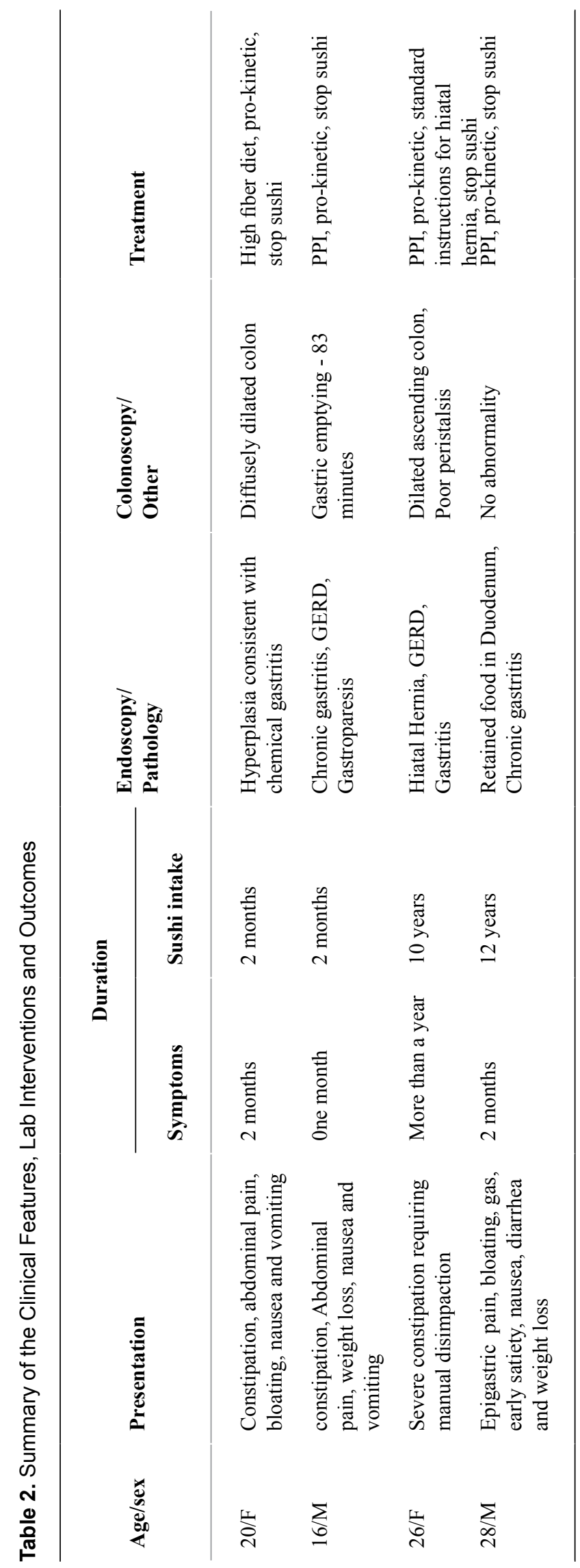


Table 3. Systemic Effects due to Mercury Overexposure (Taken From Multiple Resources)

$\begin{array}{ll}\text { Cardiovascular system } & \begin{array}{l}\text { Ischemic heart disease } \\ \text { Hypertension }\end{array} \\ & \text { Impairment of the peripheral vision } \\ \text { Nervous System } & \text { Dysesthesias - "pins and needles" sensations in the hands, feet and around } \\ \text { the mouth } & \text { Lack of coordination of movements } \\ & \text { Emotional disturbances } \\ & \text { Impairment of speech, hearing, walking } \\ & \text { Muscle weakness } \\ & \text { Immuno-suppression } \\ & \text { Autoimmune responses } \\ \text { Immune System } & \text { Still Births in Manimata city in Japan in 1950s } \\ & \text { Impaired neurological development } \\ & \text { Mental retardation, Cerebellar ataxia, Primitive reflexes, Dysarthria, } \\ \text { Fetus, infants, Young children } & \text { Hyperkinesias, Autism } \\ \text { Impairment of cognitive thinking, memory, attention, language, fine motor } & \text { and visual spatial skills } \\ & \end{array}$

last few months. Her bowel habits varied from no bowel movement for weeks to infrequent bowel movements with very little stool each time. She also reported manual disimpaction of stools. The patient had a history of eating sushi almost every day for a long time. Her physical examination was within normal limits. Her laboratory (CBC, CMP, hepatitis panel and celiac panel) and radiological work up were negative. Her EGD showed hiatal hernia and gastritis and biopsy revealed mild foveolar hyperplasia. Her colonoscopy showed normal mucosa with dilated ascending colon and poor peristalsis. She was treated with laxatives, pro-kinetics and a change of diet with remarkable improvement.

\section{Case 4}

A 28-year-old male presented with epigastric abdominal pain associated with bloating, gas and early satiety; episodes of nausea, diarrhea and a $30 \mathrm{lb}$ weight loss for two months. The patient had a history of eating sushi and eel for the last 12 years. Physical examination was normal. His laboratory (CBC, CMP, ESR, CRP, liver function tests, iron panel and celiac panel) and radiological work up were normal. EGD showed retained food in stomach and duodenum, mild chronic gastritis and GERD. Biopsy of antral mucosa revealed mild chronic inflammation. Colonoscopy was normal. He was started on low fiber diet, pro-kinetic and proton pump inhibitor and advised to stop eating sushi. The patient reported significant improvement in his symptoms in two weeks.

Although the clinical presentation varied, these young patients had a history of frequent sushi intake, and stopping/ avoiding sushi, in addition to other conservative and symptomatic management, contributed to symptomatic relief in two to three months. They never reported experiencing similar symptoms for prolonged duration. The pathology and other lab findings were nonspecific (Table 2).

\section{Discussion}

The regulation of intestinal motility is a complex phenomenon and it depends on 1), smooth muscle tone; 2), status of the intrinsic and extrinsic components of the enteric nervous system (ENS); 3), levels of hormones and circulating substances like prostaglandin, amines, peptides; 4), intestinal cells of Cajal, which serve as pacemakers of the GI tract and coordinate intestinal transit $[10,11]$. The central nervous system further influences the enteric nervous system via neuronal communications. Dysfunction of any of these components results in intestinal or colonic dysmotility. The patients in our case reports have a common factor of high $\mathrm{Hg}$ consumption from sushi as the cause of their symptoms. This 
Table 4. EPA Recommendations for Fish Consumption Based on Hg Levels (Taken From Multiple Resources)

\begin{tabular}{lll} 
Hg Level & Type of fish & Recommendation \\
\hline High & $\begin{array}{l}\text { King Mackerel, Tuna steaks, Sushi grade tuna, swordfish, Tile fish, } \\
\text { Shark, Orange roughy, Marlin, Grouper, Chilean sea bass }\end{array}$ & Do not eat \\
Low & $\begin{array}{l}\text { Butter fish, Cat fish, Cod, Crab, Croaker (Atlantic), Flounder, } \\
\text { Haddock, Jack smelt, Mackerel (North Atlantic), Mullet, Mussels, } \\
\end{array}$ & Perch (Ocean or White), Scallops, Shad (American), Sole, Squid, \\
& Trout (fresh water), Tuna (canned light), White fish 2 serving/week \\
& Anchovies, Clams, Crayfish/Crawfish, Hake, Herring, Oysters, & Eat up to 5 serving/week \\
Very low Hg & Pollock, Sardines, Tilapia, Whiting, Shrimp
\end{tabular}

led us to review its effects on intestinal motility.

\section{Sushi as a source of $\mathbf{H g}$}

Sushi has three active ingredients that could contribute to intestinal dysmotility associated with frequent consumption: 1), Raw fish; 2), Type of fish; 3), Rice. Raw fish used in sushi can harbor nematodes such as Eustrongylidia, Diphyllobothrium and Anisakiasis. Even though nematode related IPO is common in the rest of the world, very few cases are reported annually in the US due to stringent food safety regulation. Tuna fish, which is one of the most commonly used fish in sushi, is known to harbor high levels of $\mathrm{Hg}$ due to tuna's position at the top of the marine food chain $[12,13]$. Horvat et al and others reported significant levels of $\mathrm{Hg}$ in rice cultivated in $\mathrm{Hg}$ contaminated areas [14, 15].

\section{Tuna and high Hg consumption}

Mercury is present as a trace element in nature and added to the environment as a byproduct of pollution. In water, it diffuses into the water column, or is converted into $\mathrm{MeHg}$ via sulfate processing bacteria [16]. This is a key processing step in the food chain as the $\mathrm{MeHg}$ is more toxic and has a longer half life. The sulfate processing bacteria either excrete the $\mathrm{MeHg}$ again into the water, or are themselves consumed by plankton. This process results in high levels of $\mathrm{MeHg}$ in the next hierarchical organisms [12]. Bodaly et al reported that the concentration of $\mathrm{MeHg}$ in the biosphere increases at each level of the food chain [17]. This process, known as bio-magnification, can result in toxic levels in consumers [16]. The concentrations may reach up to a million times higher than what are present in water. Mercury methylated by microorganisms bio-accumulates, reaching high concentrations in predatory fishes such as tuna [13]. Lowenstein and his colleagues measured the $\mathrm{Hg}$ content of tuna sushi samples in New York, New Jersey and Colorado. The mean $\mathrm{Hg}$ concentrations of all samples exceed the maximum daily consumption considered safe by the US Environmental Protection Agency (EPA) [9].

\section{Mercury and intestinal dysmotility}

The Food and Drug Administration (FDA) has been issuing warnings on $\mathrm{Hg}$ levels in swordfish since 1986. It was reported that certain sea foods might contain levels of $\mathrm{Hg}$ harmful to the nervous system of a developing fetus, the developmental aspects of young children, and even to adults. The epidemic of MeHg poisoning in Minamata, Japan stood as the best example of bioaccumulation of toxins in the food chain.

According to Aberg et al and Rahola et al, when humans ingest $\mathrm{MeHg}$ via fish, $95 \%$ of it is readily absorbed from the GI tract into the blood stream due to its high lipid solubility and firm attachment to the thiol group of cysteine residues [18-20]. This attached $\mathrm{Hg}$ is resistant to elimination by cooking and cleaning and the levels take years to drop [16]. Once it enters the gastrointestinal tract of the consumer, the $\mathrm{MeHg}$ is maintained at high levels and for long duration via enterohepatic cycling. The rest (5\%) undergoes demethylation to mercuric mercury $\left(\mathrm{Hg}^{2+}\right)$ in vivo by tissue macrophages and intestinal flora, in fetal tissue by a yet unidentified mechanism, and in vitro by free radicals [19-22]. It was shown in mice models, that both $\mathrm{MeHg}$ and $\mathrm{Hg}^{2+}$ have strong affinity for thiol groups of amino acids and enzymes. The $\mathrm{MeHg}-$ cysteine complex readily crosses the blood brain barrier and placenta, and gets distributed throughout the body via an organic anion, chloride and calcium ion mediated transport systems. Studies have shown that $\mathrm{Hg}$ is taken up in the periphery by all nerve endings and rapidly transported through 
the axons to the spinal cord and brainstem [23, 24]. Mercury acts as a neurotoxin causing psychological and neurological problems. $\mathrm{MeHg}$ is slowly bio-transformed to inorganic $\mathrm{Hg}$ in the brain. It has been hypothesized that the long half-life of inorganic $\mathrm{Hg}$ in the brain and/or $\mathrm{MeHg}$ itself mediates the toxic effects in human via induction of mitochondrial change, lipid peroxidation, microtubule disruption and inhibition of protein synthesis [25]. Due to nonspecific inhibition of enzymes, both $\mathrm{MeHg}$ and $\mathrm{Hg}^{2+}$ affect membrane permeability and nerve conduction. The affect of $\mathrm{MeHg}$ and $\mathrm{Hg}^{2+}$ on signaling pathways is currently not well defined.

In our series of case reports, all possible causes of dysmotility were ruled out via thorough medical work up. The laboratory, radiological and histological findings were normal. Two of our patients had dilated colons and others displayed symptoms suggestive of CID. A working diagnosis of gastrointestinal dysmotility was made in these patients following laboratory, radiological and endoscopic investigation. Even though a direct cause-effect relation cannot be established in these patients, avoiding sushi with conservative and symptomatic management provided relief. We hypothesize that $\mathrm{Hg}^{2+}$ and $\mathrm{MeHg}$ affected the neuromuscular function of the GI tract in these patients, causing abnormalities in motility, ultimately resulting in constipation, abdominal pain, dysmotility, and bloating.

\section{Nematode and intestinal dysmotility}

Raw fish infested with nematodes and used in making sushi is suggested as the culprit in mechanically non-obstructive intestinal pseudo-obstruction in certain parts of the world. Few cases of IPO have been reported due to raw and undercooked fish. A nematode, mainly the third stage larval Anisakis or Pseudoterranova or Contracecum is the most implicated etiology. In many of these case reports, the pathology revealed an eosinophillic granuloma (EG) with a dead nematode detected under the microscope, and/or abdominal X-ray showed an air fluid level without an anatomical obstruction [26-28]. Boiling, burning, preserving in salt or vinegar, and freezing overnight destroy this worm infestation. None of our patients had EG or air fluid levels.

\section{Mercury and its systemic effects}

The multi systemic affects of $\mathrm{Hg}$ are summarized in Table 3.

\section{Public health importance [12]}

According to EPA, the acceptable amount of $\mathrm{Hg}$ for weekly consumption by an adult of $154 \mathrm{lbs}$ is approximately $49 \mathrm{mi}$ crograms, which is equivalent to six pieces of sushi weekly (Table 4). People weighing less than $154 \mathrm{lbs}$ should consume even smaller amounts of sushi. Mercury exposure among women of childbearing age is a matter of concern. The data from the CDC's Third Report for 1999 - 2002 concluded that one in 17 women of childbearing age have $\mathrm{Hg}$ in their blood above 5.8 micrograms per liter of blood. This is a level that could pose a risk to a developing fetus. Nearly one in 10 women of reproductive age in the US has $\mathrm{Hg}$ levels in her blood at or above this level. The placenta transports $\mathrm{Hg}$ to the developing fetus, causing permanent damage to the developing brain and nervous system including mental retardation, seizure disorders, cerebral palsy, blindness and deafness. A small quantity can also pass from breast milk. Thus, a considerable amount of $\mathrm{Hg}$ exposure early in life may affect the development of the brain or nervous system and may cause problems in learning.

In 2004, both the FDA and the EPA proposed the following recommendations for young children, breast feeding mothers, and women who are pregnant or planning pregnancy. 1), Avoid shark, swordfish, King mackerel, or tilefish; 2) Eat up to 12 ounces per week of shrimp, canned light tuna, salmon, pollock, and catfish as these are lower in mercury; 3) Avoid white tuna as it has more mercury than canned light tuna; 4) Serve smaller portions to young children; 5), Consume no more than the recommended serving size of $4-6$ ounces for adults.

\section{Conclusion}

Mercury is possibly a common cause of intestinal dysmotility and can have a variable presentation. In this review the etiology, clinical features and management of intestinal dysmotilities was briefly summarized and its correlation with frequent consumption of sushi was explained. Other $\mathrm{Hg}$ related systemic effects were broadly reviewed. Avoiding sushi and related foods demonstrated a significant benefit in our CID patients. The normal histological and laboratory findings confirmed the nonspecific nature of presentation and the difficulty in accurately diagnosing and treating these patients.

In an era of widespread popularity of Asian foods in the US, clinicians should be aware of the nonspecific presentation and subsequent effects associated with $\mathrm{Hg}$ exposure via consumption of contaminated foods. Moreover, they also should keep in mind that the risk from mercury by eating fish and shellfish is not a health concern for those who eat in moderation. Infants and young children exposed during periods of rapid brain development are more susceptible to the toxic effects of MeHg. We predict that the incidence of intestinal dysmotility due to $\mathrm{Hg}$ in frequent sushi eaters would be higher if complementary studies were done in all patients with unidentified cause for related symptoms.

\section{Sources of Funding for Project}

N/A. 


\section{Conflict Delineations}

No conflict of interest.

\section{References}

1. Parkman HP, Doma S. The Importance of Gastrointestinal Motility Disorders. Practical gastroenterology. 2006;30(9):23-40.

2. Higgins PD, Johanson JF. Epidemiology of constipation in North America: a systematic review. Am J Gastroenterol. 2004;99(4):750-759.

3. Alwan MH, van Rij AM. Acute colonic pseudo-obstruction. Aust N Z J Surg. 1998;68(2):129-132.

4. Clarke HD, Berry DJ, Larson DR. Acute pseudo-obstruction of the colon as a postoperative complication of hip arthroplasty. J Bone Joint Surg Am. 1997;79(11):16421647.

5. Stanghellini V, Cogliandro RF, de Giorgio R, Barbara G, Salvioli B, Corinaldesi R. Chronic intestinal pseudoobstruction: manifestations, natural history and management. Neurogastroenterol Motil. 2007;19(6):440-452.

6. Isaacs P, Keshavarzian A. Intestinal pseudo-obstruction-a review. Postgrad Med J. 1985;61(722):1033-1038.

7. Toxocological Profile for Mercury. http://www.atsdr. cdc.gov/ToxProfiles/tp46.pdf. Retrieved on: June 25, 2010.

8. Nierenberg DW, Nordgren RE, Chang MB, Siegler RW, Blayney MB, Hochberg F, Toribara TY, et al. Delayed cerebellar disease and death after accidental exposure to dimethylmercury. N Engl J Med. 1998;338(23):16721676.

9. Lowenstein JH, Burger J, Jeitner CW, Amato G, Kolokotronis SO, Gochfeld M. DNA barcodes reveal speciesspecific mercury levels in tuna sushi that pose a health risk to consumers. Biol Lett. 2010;6(5):692-695.

10. De Giorgio R, Sarnelli G, Corinaldesi R, Stanghellini $\mathrm{V}$. Advances in our understanding of the pathology of chronic intestinal pseudo-obstruction. Gut. 2004;53(11):1549-1552.

11. He CL, Burgart L, Wang L, Pemberton J, Young-Fadok T, Szurszewski J, Farrugia G. Decreased interstitial cell of cajal volume in patients with slow-transit constipation. Gastroenterology. 2000;118(1):14-21.

12. FDA US Food \& Drug Administration. What You Need to Know About Mercury in Fish and Shellfish March 2004. http://www.fda.gov/food/resourcesforyou/consumers/ ucm110591.htm. Retrieved on 10/10/2011.

13. Morel MM, Kraepiel ML, Amyot M. The chemical cycle and bioaccumulation of mercury. Annu. Rev. Ecol.
Syst. 1998;29:543-566.

14. Horvat M, Nolde N, Fajon V, Jereb V, Logar M, Lojen $\mathrm{S}$, Jacimovic R, et al. Total mercury, methylmercury and selenium in mercury polluted areas in the province Guizhou, China. Sci Total Environ. 2003;304(1-3):231-256.

15. Feng X, Li P, Qiu GL et al. Human exposure to methylmercury through rice intake in mercury mining areas, Guizhou province, China. Environ. Sci. Technol. 2008;42:326-332.

16. Mercury in the Environment. Fact Sheet 146-00 (October 2000). http://www.usgs.gov/themes/ factsheet/ 14600/ index.html. Retrieved on: June 25,2011.

17. Bodaly RA, Fudge RJ. Uptake of mercury by fish in an experimental boreal reservoir. Arch Environ Contam Toxicol. 1999;37(1):103-109.

18. Aberg B, Ekman L, Falk R, Greitz U, Persson G, Snihs JO. Metabolism of methyl mercury $(203 \mathrm{Hg})$ compounds in man. Arch Environ Health. 1969;19(4):478-484.

19. Rahola T, Hattula T, Korolainen A, Miettinen JK. Elimination of free and protein-bound ionic mercury (20Hg2+) in man. Ann Clin Res. 1973;5(4):214-219.

20. Committee on the Toxicological Effects of Methylmercury, Board on Environmental Studies and Toxicology, National Research Council (2000). National Academy Press, Washington D.C.

21. Dunn JD, Clarkson TW. Does mercury exhalation signal demethylation of methylmercury? Health Phys. 1980;38(3):411-414.

22. Yasutake A, Hirayama K, Inoue M. Interaction of methylmercury compounds with albumin. Arch Toxicol. 1990;64(8):639-643.

23. Arvidson B. Inorganic mercury is transported from muscular nerve terminals to spinal and brainstem motoneurons. Muscle Nerve. 1992;15(10):1089-1094.

24. Arvidson B. Retrograde axonal transport of mercury. Exp Neurol. 1987;98(1):198-203.

25. Yoshino Y, Mozai T, Nakao K. Biochemical changes in the brain in rats poisoned with an alkymercury compound, with special reference to the inhibition of protein synthesis in brain cortex slices. J Neurochem. 1966;13(11):1223-1230.

26. Georgescu EF, Vasile I, Ionescu R. Intestinal pseudo-obstruction: an uncommon condition with heterogeneous etiology and unpredictable outcome. World J Gastroenterol. 2008;14(6):954-959.

27. Takabe K, Ohki S, Kunihiro O, Sakashita T, Endo I, Ichikawa Y, Sekido H, et al. Anisakidosis: a cause of intestinal obstruction from eating sushi. Am J Gastroenterol. 1998;93(7):1172-1173.

28. Bouree P, Paugam A, Petithory JC. Anisakidosis: report of 25 cases and review of the literature. Comp Immunol Microbiol Infect Dis. 1995;18(2):75-84. 